\title{
DYNAMIC ANALYSIS OF OFFSHORE STRUCTURES UNDER IMPACT LOAD USING INTERFACE FINITE ELEMENT METHOD
}

\author{
[ANIS A. MOHAMED ALI ${ }^{1}$ and JAFFAR A. KADIM ${ }^{2}$ ]
}

\begin{abstract}
The main object of this paper is to fit with high degree of accuracy the true structure response by considering the concept of interface element which is used to simulate three dimensional soil-structure interaction in the dynamic analysis, therefore the dolphin of khor Al-Amaya berth no. 8 is analyzed as a case study. The (p-y), (t-z), and (q-z) curves which are adopted by American Petroleum Institute (API) are used to find normal and tangential interface moduli and end bearing modulus. For this purpose, a computer Fortran program Offshore_Inter has been built to obtain the required solution. The subspace iteration method is used to find the free vibration solution while Newton-Raphson modified method combined with Newmark's method is applied to get the nonlinear forced vibration solution. For both solutions, the conjugate gradient algorithm is used as a solver of the dynamic problem. A parametric study has been carried out including different soil type, soil engineering properties, loading time effect and the results are given in tables and graphs. The dynamic structural response is compared with the results of previous studies on the same structure and with elastic and Reese solution to show the difference between the different formulations. From obtained results, it is shown the interface solution increases the structure response by more than $80 \%$ comparing with Winkler method based on same curves mentioned above. Pile deflection and bending moment values along pile length are relatively increased many times than the solution obtained from elasticity theory and Reese solution. Finally, the increased soil strength will largely degrease the structure response for all soils.
\end{abstract}

Keywords - merican Petroleum Institute API, Newmark's method, Conjugate gradient algorithm, Reese solution, Winkler method, Pile response.

\section{Introduction}

There are many types of offshore structures such as gravity, jack-up, tension leg platform, and jacket platforms. The jacket, or template, structures are still the most common offshore structures used for drilling and oil production. Fixed jacket structures consist of tubular members interconnected to form a three-dimensional space frame so that these structures resist the static and dynamic loads. One of the most important dynamic loads is impact loading due to ship berthing and mooring. The nature of this impact load is lateral cyclic load may be considered as one way [1].The analysis of a pile under combined loads is performed and utilized by various methods ranging from elastic to plastic theories [2].

\footnotetext{
${ }^{1}$ Engineering college/ Basrah University

Iraq

2 Engineering college/ Basrah University

Iraq
}

The predicating of lateral bearing capacity of pile have been investigated by many researches such as Matlock and Reese (1960). They were the first few to develop design curves for predicting the deflection of piles within the range of the elastic compression of the soil. Hansen (1961) proposed a method of predicting the ultimate lateral load of rigid piles based on the theory of plasticity. Broms (1964) presented a method to determine the ultimate lateral capacity of loaded (short, intermediate and long) pile for different soil types and for two pile cap cases; free head and fixed [3]. The p-y curve method has been developed by Matlock et al. (1970) for soft clays, then by Reese et al. (1974) for sands, and again by Reese et al. (1975) for stiff clay. [4]. The concept of interface element (zero thickness) was first introduced by Goodman in 1968 [5] when it was used in rock mechanics into two dimensional analysis. After that, this concept is extensively used in many branches in engineering fields.

\section{FORMULATION OF THE PROBLEM}

Offshore structures are usually subjected to a heavy impact loads exist during ship berthing. The magnitude and variation of these loads depend on many factors and discussed in details in many researches and studies. For the present paper, the dolphin of khor Al-Amaya berth no. 8 is analyzed to impact loads by considered an oil tanker of 330000 DWT at $60 \%$ cargo and using a Bridgestone C2000 $\mathrm{H}$ cell as fender type. This structure is taken as case study because this structure is actual structure and was analyzed by many researches with different formulations of soilstructure interaction [6,7]. The Structure, soil, and interface formulation are presented in next paragraph.

\section{A. Soil Formulation}

The soil is represented by brick element that has eight nodes so that each node has three degree of freedom represents the translation motion in three global coordinates. The soil boundary must be established at sufficient distance from the edge of the pile, this distance should be large enough but not less than a distance at least equal to five times the pile diameter or out of envelope load region $[8,13]$.

\section{B. Structure Formulation}

The structure is represented by flexure frame element that has prismatic cross and it connect to two nodes. This element is connected to other elements only at the nodes. Each node has six degree of freedom, three translation and three rotations, in which the positive direction of rotation is based on right hand role [9]. 


\section{Interface Formulation}

Various modes of deformation of an interface under static and dynamic loadings had been developed in past [10] such as stick, slip, and debonding. In this study, both normal and tangential motion are allowed in which no slip is prevented between pile and soil and normal stress is always considered compressive. But during pile movements as result of applied cyclic loads a tension stress behind the pile near seabed is developed and when the soil cannot resist this active stress a gap formation occurs. The gap, which had formed around the pile as the soil was displaced by its entry, extended to a depth ranging from 3 to 8 times the pile diameters according to various references [5].

\section{C.1 Derivation of 3D Interface Element}

A typical interface zero thickness element for 3D applications that is based on the joint element proposed by Goodman [5] as shown in Fig. 1. The strain at any point in the element may be defined by the local tangential and normal relative displacements between the pile and the soil that is given by:

$$
\{\varepsilon\}=[B] \times\{\delta\}
$$

where

$\{\varepsilon\}=\left\{\begin{array}{lll}\varepsilon_{t} & \varepsilon_{n 1} & \varepsilon_{n 2}\end{array}\right\}^{T}$

$[B]=\left[\begin{array}{cccccccccccc}N_{1} & 0 & 0 & N_{2} & 0 & 0 & -N_{1} & 0 & 0 & -N_{2} & 0 & 0 \\ 0 & N_{1} & 0 & 0 & N_{2} & 0 & 0 & -N_{1} & 0 & 0 & -N_{2} & 0 \\ 0 & 0 & N_{1} & 0 & 0 & N_{2} & 0 & 0 & -N_{1} & 0 & 0 & -N_{2}\end{array}\right]$

$\{\delta\}^{T}=\left[\begin{array}{llllllllllll}u_{1 p} & v_{1 p} & w_{1 p} & u_{2 p} & v_{2 p} & w_{2 p} & u_{1 s} & v_{1 s} & w_{1 s} & u_{2 s} & v_{2 s} & w_{2 s}\end{array}\right]$

$N_{1}=(1-\xi) / 2$,

$N_{2}=(1+\xi) / 2$,

$\varepsilon_{t}=$ tangential strain,

$\varepsilon_{n 1}=$ first normal strain, and $\varepsilon_{n 2}$ :second normal strain, $[B]=$ shape function matrix,

$\delta=$ local nodal displacements of the pile and the soil at two ended nodes,
$N_{1}$ and $N_{2}$ are shape functions,

$\xi$ : local coordinate changing between -1 and 1 to represent the location of any point within the interface element.

the constitutive stress relative displacements relations are given as:

$$
\{\sigma\}=[D] \times\{\varepsilon\}
$$

where

$$
\{\sigma\}=\left\{\begin{array}{lll}
\sigma_{t} & \sigma_{n 1} & \sigma_{n 2}
\end{array}\right\}^{T}
$$$$
[D]=\left[\begin{array}{ccc}
k_{t} & 0 & 0 \\
0 & k_{n} & 0 \\
0 & 0 & k_{n}
\end{array}\right]
$$

$[D]_{=}$constitutive stress relative displacements relation, and $k_{t}$ and $k_{n}$ tangential and normal modulus

$\sigma_{t}=$ tangential stress;

$\sigma_{n 1}=$ first normal stress, and $\sigma_{n 2}$ is second normal stress.

The actual behavior of interface element during loading process depends upon the characteristics properties of surrounding materials (soil and structure) in other words the weaker material [11]. In the present paper, these moduli are derived from the (p-y) and (t-z) curves that adopted by American Petroleum Institute (API) in the analysis of offshore structures due to static and cyclic loading [12].

Using virtual work principle, the interface element stiffness matrix $\left[K_{L I}\right]$ may be written as:

$$
\left[K_{L I}\right]=\int_{A}[B] \times[D] \times[B] d A
$$

Since the above integration through surface area of interface element cannot evaluate analytically, a numerical integration scheme is carried using gauss integration method. Therefore, the interface stiffness matrix is evaluated from the following:

$$
\left[K_{L I}\right]=\sum_{i=1}^{n-\text { Gauss }}\left([B]^{T} \times[D] \times[B] \times w \times A\right) / 2
$$

where $A$ is the area of circular cylinder of interface element, sometimes referred as determinate of Jacobean.

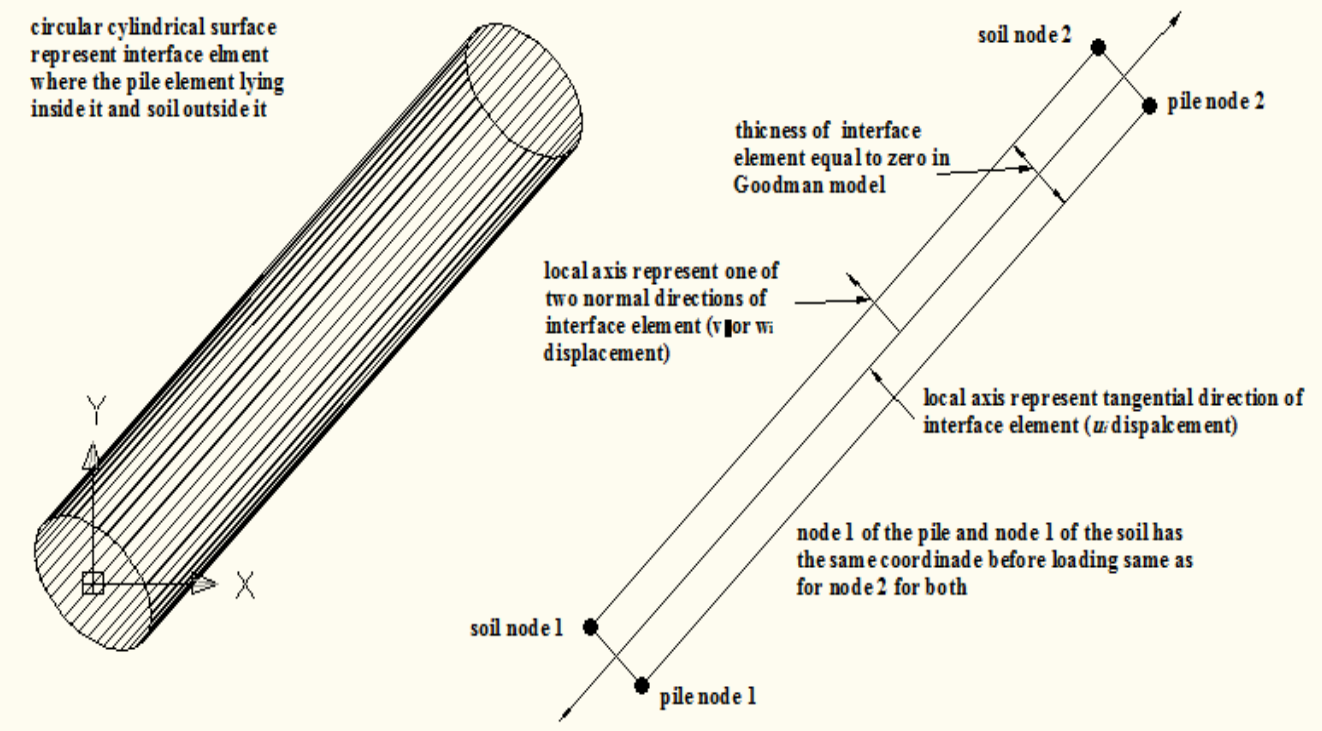

Fig. 1 Interface element details 


\section{End (Tip Point) Bearing Element}

The end bearing element is introduced to take into account the interaction between the end pile and the soil. It consists of two nodes, one represents the pile tip point and the other indicates to the soil, and its alignment is the same as for the pile. It takes translation deformations only. The stiffness modulus is based on (q-z) curve for both clay and sand soils. The size of stiffness matrix in local coordinates is $(2 \times 2)$ and it is calculated as:

$$
\left[K_{L P}\right]=k_{z} \times\left[\begin{array}{cc}
1 & -1 \\
-1 & 1
\end{array}\right]
$$

\section{METHOD OF SOLUTION}

The global stiffness and mass (As in interface element formulation, no mass is associated to end bearing element) domain (soil+ structure+ interface) matrix are obtained by the assemblage of individual element types. The subspace iteration method is used to find the free vibration solution [14]. For soil-structure system, the nonclassical damping matrix is employed, the damping ratio of soil and structure are taken equal to $15 \%$ and $3 \%$ respectively. In this paper Rayleigh damping method is used by considering the first six eignvalues [16].

For forced vibration problem, the Newmark's beta method, also referred to as the constant acceleration method, is used for solving the forced vibration problem. At initial time both the displacement and the velocity vectors are assumed equal to zero and the initial acceleration vector is determined from the above equation. For other time, the nonlinear solution is obtained by applying the modified Newton-Raphson method.[9,14,15,16]. For both free and forced problems, the conjugate gradient algorithm is used as a solver of the dynamic problem.

\section{RESULTS AND DISCUSSION}

For the current study, the dolphin of khor Al-Amaya berth no. 8, is analyzed to impact loads that is given by AlJasim [6] for three cases which represent the same energy but different berthing velocities. From previous studies $[6,7]$, the maximum dynamic response is associated with velocity 1 . therefore, the dynamic analysis is carried for this velocity only. The obtained results are summarized in tables 1-2 and figures 2-6.

\section{A. Loading Time Effect}

It is noted that the loading time of velocity 1 has small effect in which the maximum effect is less than $4 \%$ associated to maximum base bending moment for stiff clay. This effect may be explained due to large contact time that reduced dynamic response as indicate by the previous studies $[6,7]$.For zero time connect, the response increased by different amount according to deck displacement and base reactions. The maximum influence is aroused for maximum base bending moment that increased by more than $90 \%$ compared with velocity time 1 . In addition, the maximum base shear force obtained using Winkler method is larger than interface method and this effect can be attributed to the better distribution of applied loading achieved by interface method.

\section{B. Pile Response}

Table 2 shows the maximum deflection and critical length, length from seabed corresponding to first zero pile deflection, for clayey soils using elastic $[17,18]$, interface, and Reese solution [19]. This result can be explained from the stiffness of elastic model is greater than the other models. From Figs. 2 and 3, a number of interesting points can be shown as follows:

1-The nonlinear response of pile to lateral loads using interface solution is larger.

2- The trend of elastic solution is not changed as the soil strength increasing for both soils.

3- the trend of pile deflection gutted by interface solution is similar to the trend of elastic solution, rapidly lowered with increasing soil depth.

\section{Time Response}

This results of figures 4 can be explained such that, the increasing soil strength causes increasing the domain stiffness leading to reduce in the structure response. In addition, the nonlinear effect of the domain is appeared in two time regions, near and at the loading and reloading regions, for which the maximum dynamic effect is happened. Finally, The fluctuation in the maximum deck deflection occur at the end of loading region that approximately reveal their direction for all soil types at this region.

The main conclusions are shown as follows:

1- The use of (p-y), and (t-z) curves in the deriving the nonlinear normal and tangential interface moduli are seem suitable to represent the nonlinear behavior of pile-soil interaction, and a similar sequence is obtained for $(\mathrm{q}-\mathrm{z})$ curve that used for deriving the stiffness modulus for the tip pile element.

2- The Winkler method based on (p-y), and (t-z) curves displays a lower structural response by a reasonable amount compared (more than $80 \%$ ) with the interface method using the same curves.

3- The time of load raising has an important effects on the structural response for both the Winkler and interface method but the results of first method are more sensitive (increased by $83 \%$ ) than the second method (increased by $54 \%)$.

4- The pile response is increased many times (2 to 3 ) times by using interface solution other than elastic or Reese method.

5- The vertical pile deflection in interface solution is larger by three times than the corresponding value for elastic solution and approximately (2.2) times Reese solution and then the nonlinear effects is summarized in the interface solution .

6- The effect of increasing soil strength effect is reduced the structure and pile response by a great ratio for all soil types using either the interface (reduced by $52 \%$ for sandy soils and $54 \%$ for clayey soils), or the elastic solution (reduced by $37 \%$ for sandy soils and $50 \%$ for clayey soils), but the trend or nature of solution remains unchanged with soil strength. 
Proc. of The Fifth Intl. Conf. On Advances in Civil and Structural Engineering - CSE 2016

Copyright (C) Institute of Research Engineers and Doctors, USA .All rights reserved.

ISBN: 978-1-63248-088-0 doi: 10.15224/ 978-1-63248-088-0-22

Table 3 The effect of loading time on structural response for different soil types using different problem formulation

\begin{tabular}{|c|c|c|c|c|c|c|c|c|c|}
\hline \multirow{2}{*}{$\begin{array}{c}\text { Item } \\
\text { (maximum value) }\end{array}$} & \multicolumn{2}{|c|}{ Zero contact time } & \multicolumn{2}{c|}{2.4 contact time V1 } & \multicolumn{3}{c|}{ Static (50 sec) } \\
\cline { 2 - 11 } & \multicolumn{2}{|c|}{\begin{tabular}{c} 
Interface \\
\cline { 2 - 10 }
\end{tabular}} & $\begin{array}{c}\text { Stiff } \\
\text { clay }\end{array}$ & $\begin{array}{c}\text { Dense } \\
\text { sand }\end{array}$ & Clay & $\begin{array}{c}\text { Stiff } \\
\text { clay }\end{array}$ & $\begin{array}{c}\text { Dense } \\
\text { sand }\end{array}$ & Clay & \multicolumn{2}{c|}{$\begin{array}{c}\text { Itiff } \\
\text { clay }\end{array}$} & $\begin{array}{c}\text { Dense } \\
\text { sand }\end{array}$ & Winkler \\
Clay \\
\hline Structure deflection $(\mathrm{mm})$ & 79.0 & 81.3 & 53.1 & 54.3 & 56.6 & 29.7 & 51.3 & 54.9 & 29.0 \\
\hline Base axial force $(\mathrm{kN})$ & 2071 & 2112 & 1568 & 1485 & 1513 & 887 & 1432 & 1468 & 867 \\
\hline Base shear force $(\mathrm{kN})$ & 457 & 455 & 536 & 262 & 253 & 299 & 269 & 244 & 293 \\
\hline Base bending moment( kN.m) & 2079 & 2244 & 805 & 1137 & 1219 & 450 & 1082 & 1174 & 440 \\
\hline Dynamic amplification factor & 1.54 & 1.48 & 1.83 & 1.06 & 1.03 & 1.02 & 1 & 1 & 1 \\
\hline
\end{tabular}

Table 4 The Pile Maximum Deflection and Critical length for Different Clayey Soils Using Elastic, Interface, and Reese solution

\begin{tabular}{||c||c|c|c||c|c|c||}
\hline \multicolumn{1}{|c||}{$\begin{array}{c}\text { Method of } \\
\text { Solution }\end{array}$} & \multicolumn{3}{c||}{ Maximum deflection $(\mathrm{mm})$} & \multicolumn{3}{c||}{ Critical Length (m) } \\
\cline { 2 - 7 } & Soft Clay & Firm Clay & Stiff Clay & Soft Clay & Firm Clay & Stiff Clay \\
\hline \hline Elastic Solution & -12.39 & -7.13 & -3.76 & 5.66 & 5.66 & 6.01 \\
\hline Program Fortran & -30.09 & -19.90 & -10.60 & 15.71 & 13.80 & 11.15 \\
\hline Matlock and Reese & -16.37 & -9.42 & -4.97 & 14.15 & 11.89 & 10.00 \\
\hline Fortran/Elastic Ratio & 2.43 & 2.79 & 2.82 & 2.78 & 2.44 & 1.86 \\
\hline Fortran/Reese Ratio & 1.84 & 2.11 & 2.13 & 1.11 & 1.16 & 1.11 \\
\hline
\end{tabular}

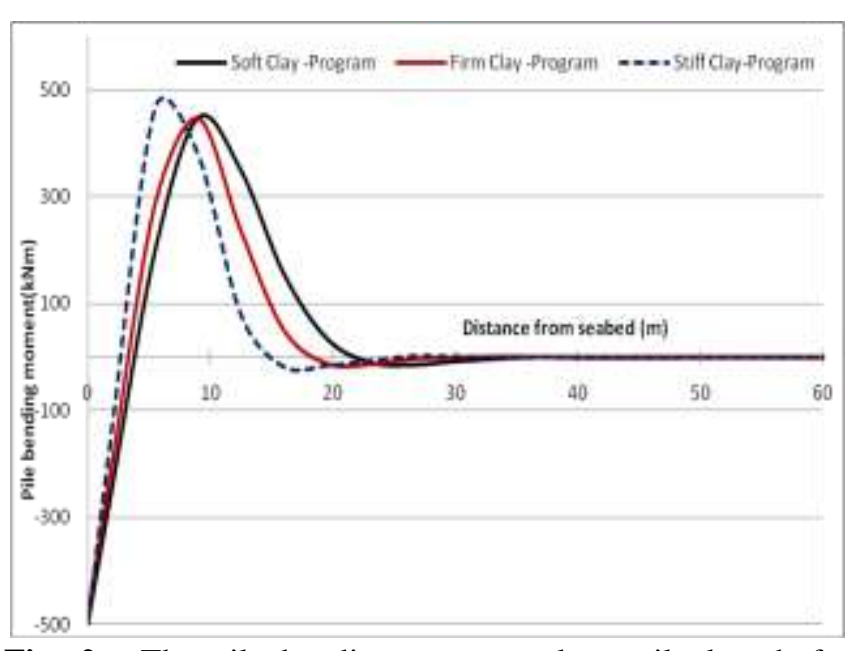

Fig. 2.a The pile bending moment along pile length for clayey soils using interface solution.

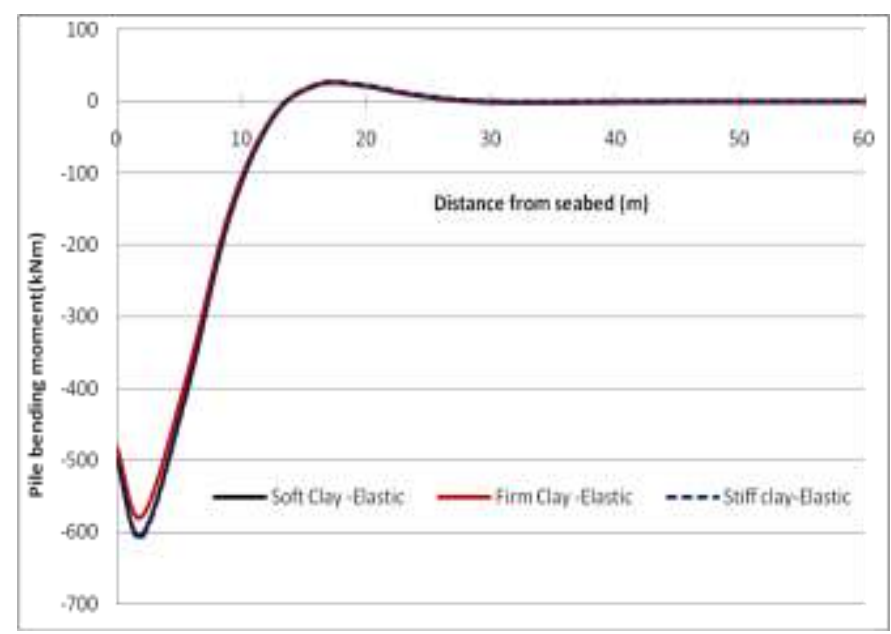

Fig. 2.b The pile bending moment along pile length for clayey soils using elastic solution

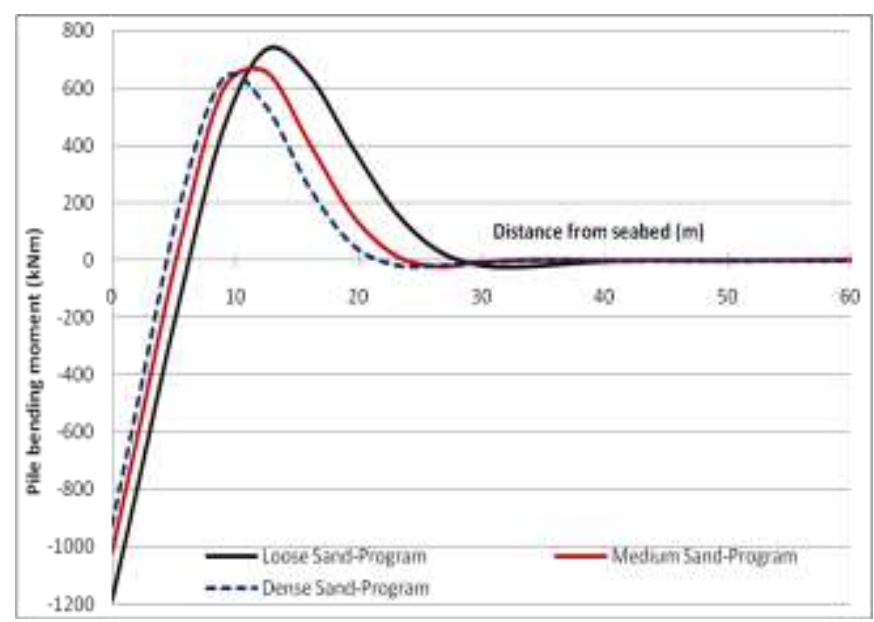

Fig. 2.c The pile bending moment along pile length for sandy soils using interface solution.

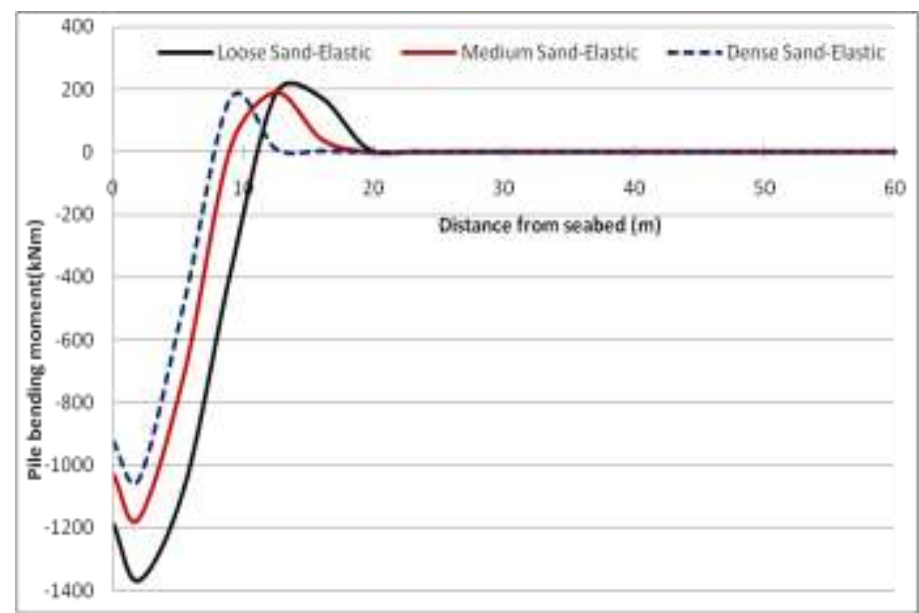

Fig. 2.d The pile bending moment along pile length for sandy soils using elastic solution 
Proc. of The Fifth Intl. Conf. On Advances in Civil and Structural Engineering - CSE 2016

Copyright $(\odot$ Institute of Research Engineers and Doctors, USA .All rights reserved.

ISBN: 978-1-63248-088-0 doi: 10.15224/ 978-1-63248-088-0-22

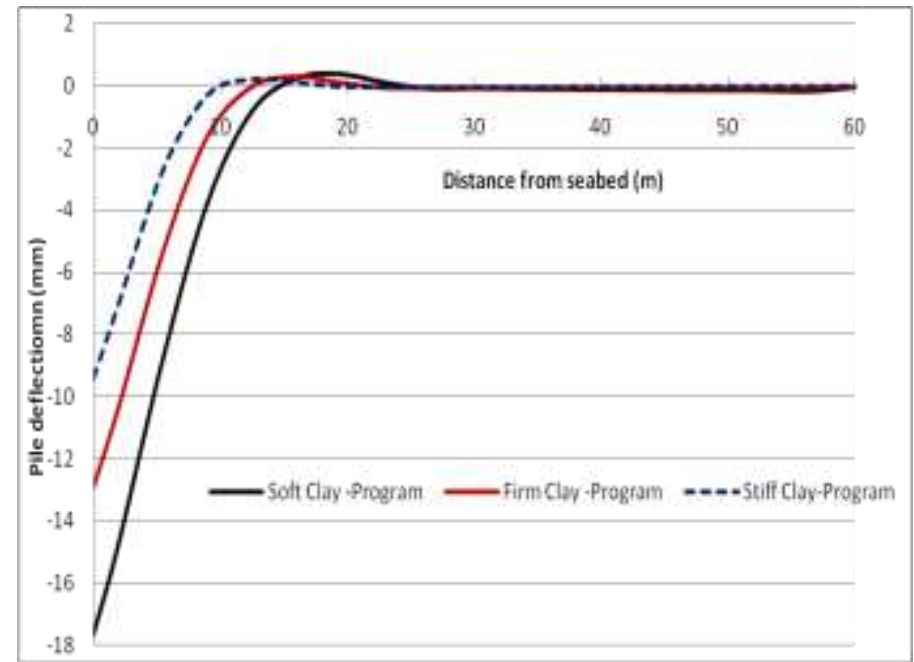

Fig. 3.a The pile deflection along pile length for clayey soils using interface solution.

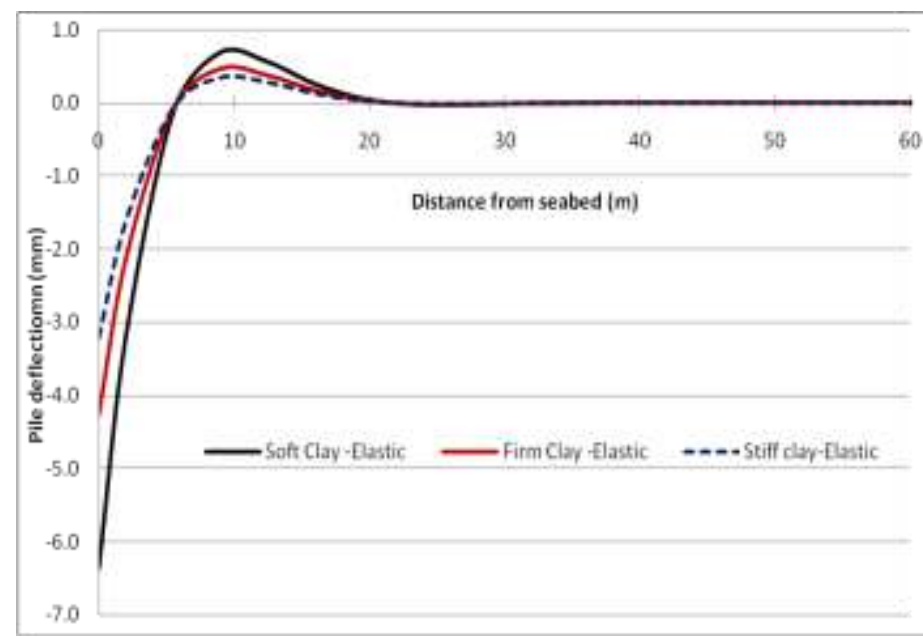

Fig. 3.b The pile deflection along pile length for clayey soils using elastic solution.

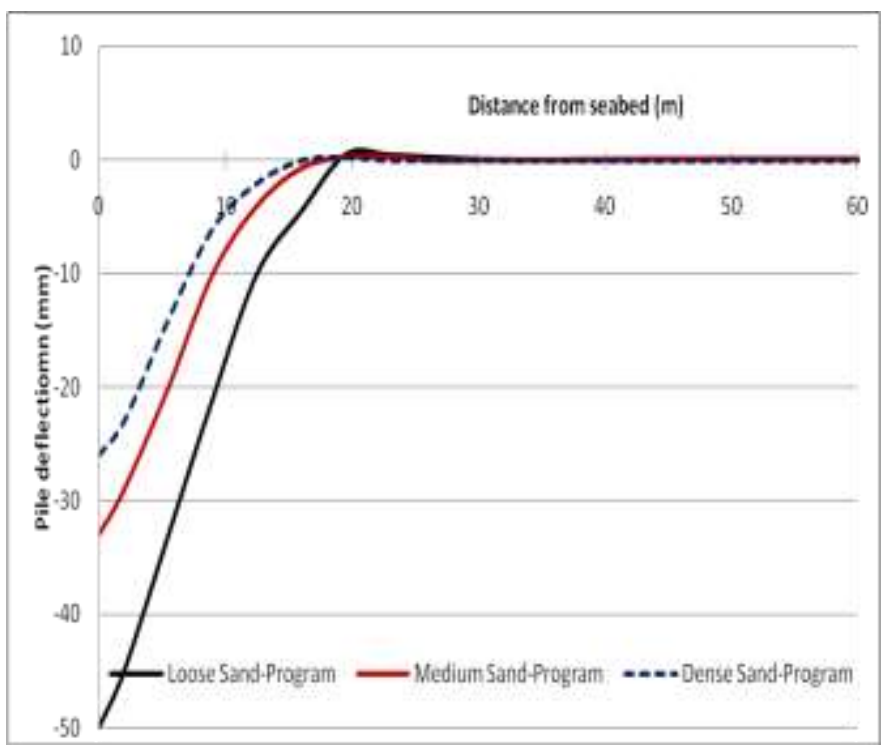

Fig. 3.c The pile deflection along pile length for sandy soils using interface solution

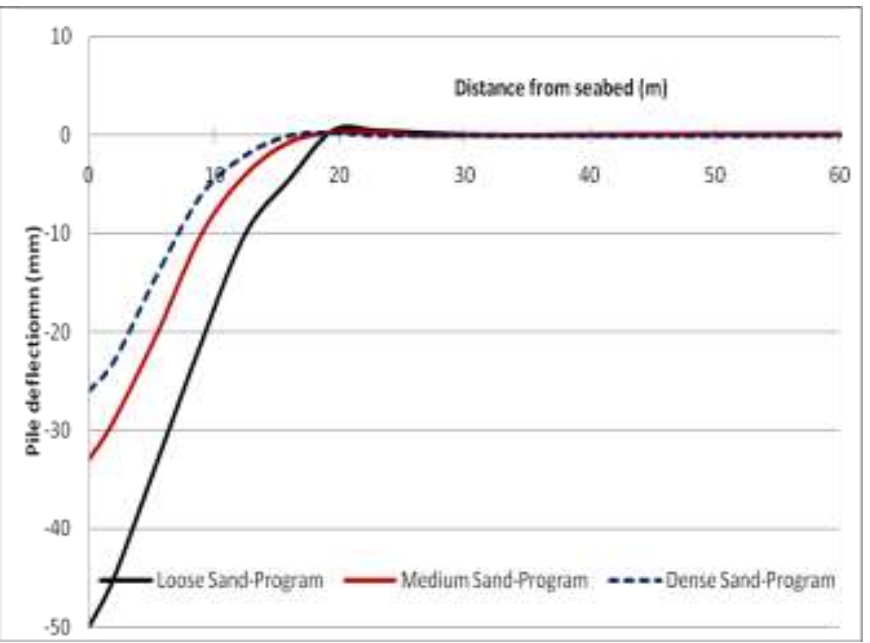

Fig. 3.d The pile deflection along pile length for sandy soils using elastic solution

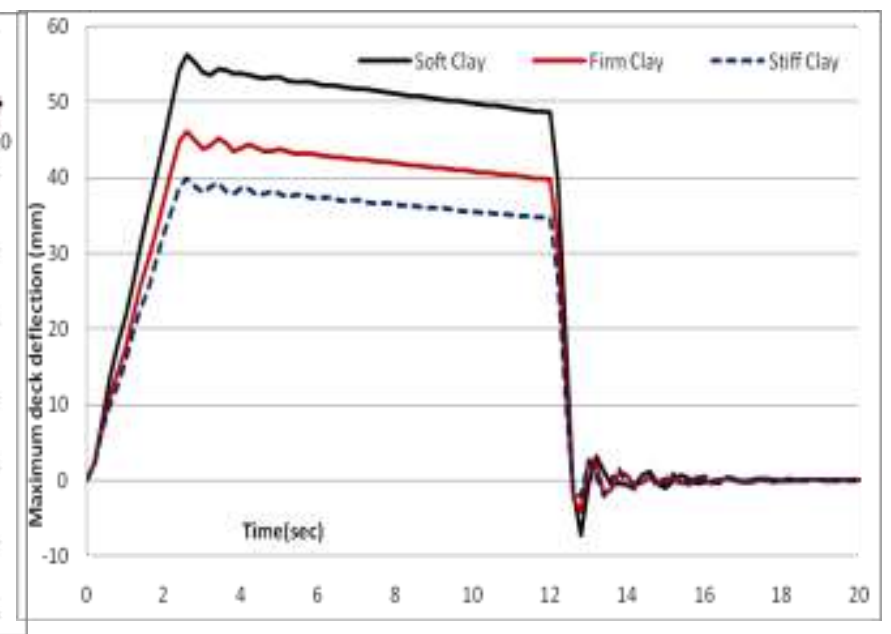

Fig. 4.a The maximum deck deflection with time for different clayey soils.

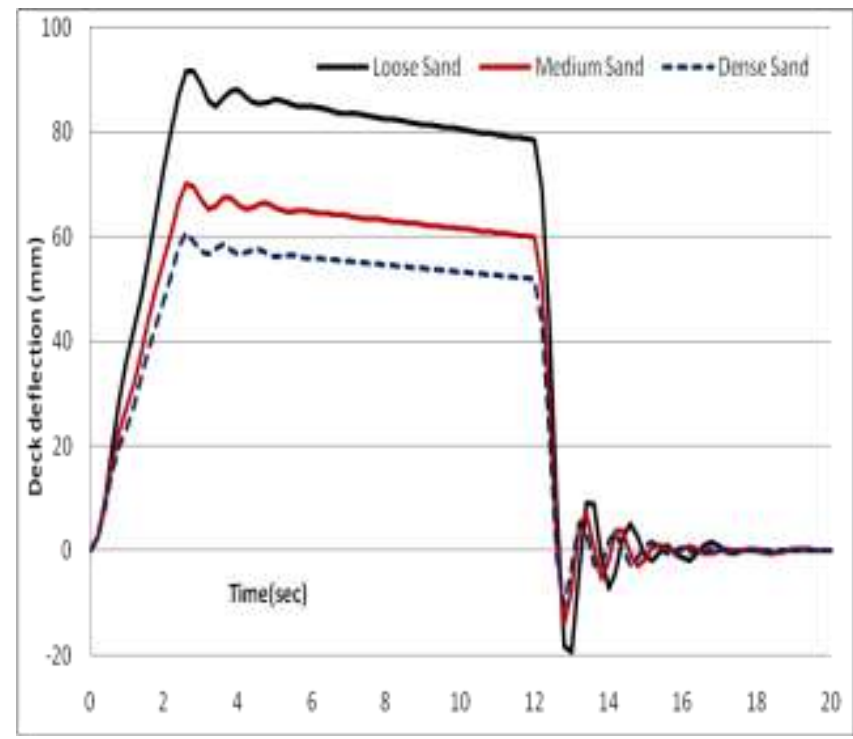

Fig. 4.b The variation of maximum deck displacement with time for different sandy soils 


\section{REFERENCES}

1-R.D. Purkayastha and S. Basack, "Response of Model Piles under Lateral Cyclic Loading", GEO Shore International Conference on Offshore and Nearshore Geotechnical Engineering, December 2-3, I999, Published by A.A. Balkema, P.O. Box 1675,3000 BR Rotterdam, Netherlands, pp. 227-232, 2000.

2-Anjum Rashid Chaudhry 1994 "Static Pile-Soil-Pile Interaction in Offshore Pile Groups", Ph. D. Eng. thesis, Brasenose College University of Oxford, England, 1994.

3-S.S. Rajashree and R. Sundaravadiveld "Gap Model of One-Way Cyclic Lateral Load on Vertical Piles in Soft Clay", GEO Shore International Conference on Offshore and Nearshore Geotechnical Engineering, December 2-3, I999, Published by A.A. Balkema, P.O. Box 1675,3000 BR Rotterdam, Netherlands, pp. 295-300, 2000.

4- M. J. Tomlinson "Pile Design and Construction Practice", 5th Ed., London, England: E \& FN SPON An Imprint of Chapman \& Hall, 2009.

5- R. E. Goodman, R. L. Taylor and T. L. Brekke "A model for the mechanics of jointed rock", Journal of the Soil Mechanics and Foundations Division, ASCE. 94. No. SM3, 637-659, 1968.

6-Samir Al-Jasim "Dynamic Analysis of Offshore Template Structures with Soil-Structure Interaction”, Ph. D., Eng. thesis, Engineering College University of Basrah, 2000.

7-H. A. Hussain "Dynamic Analysis of Offshore Structures using Finite Element Method", M. Eng. thesis, Engineering College Basrah University, 2003.

8-Zienkiewics O. C., Lewis R. W., and Stagg K. G.,"Numerical Methods in Offshore Engineering", USA: John Wiley and Son, 1978.

9- David H. Hutton "Fundamentals of Finite Element Analysis", first Ed., New York, USA: McGraw-Hill Company, 2004.

10-M. M. Zaman, C. S. Desai, and E. C. Drumm "Interface Model For Dynamic Soil-Structure Interaction", Journal of Geotechnical Engineering, Vol. 110, No. 9, pp. 1257-1273, 1984.

11- C. S. Desai, M. M. Zaman, J. G. Lightner, and H. J. Sirwardane "Thin Layer Element for Interfaces and Surfaces", International journal for numerical methods in geomechanics, Vol. 8, pp. 19-43, 1984.

12-AMERICAN PETROLEUM INSTITUTE Recommended practice for planning, designing, and constructing fixed offshore platforms (API RP2A), 21 th. Ed., USA, 2005.

13-Joseph E. Bowles, RE., S.E. "Foundation Analysis and Design”,. Fifth Ed., New York, UAS: McGraw-Hill Companies Inc, 1997.

14-S. S. Rao "The Finite Element Method In Engineering", Forth Ed., USA: Elsevier Science \& Technology Books, 2004.

15-I. M. Smith and D. V. Griffiths "Programming the Finite Element Method", Forth Ed., USA: John Wiley \&Sons, 2004.

16- Anil K. Chopra "Dynamic of Structures", Forth Ed.USA: Prentice Hall, ,USA, 2008.

17- Arnold Verruijt "Offshore Soil Mechanics", Delft University of Technology, 2005.

18- L. C. Reese and W. F. Van Impe "Single Pile and Pile Groups Under Lateral Loading”, London, UK: Taylor \&Francis Group Plc, 2007.

19- Matlock H., and Reese L.C. Generalized Solution for Laterally Loaded prior Piles, ASCE J. of Soil Mechanics and Foundation Eng. 86, SM 5 (63-91), 1960.

\section{About Author (s):}
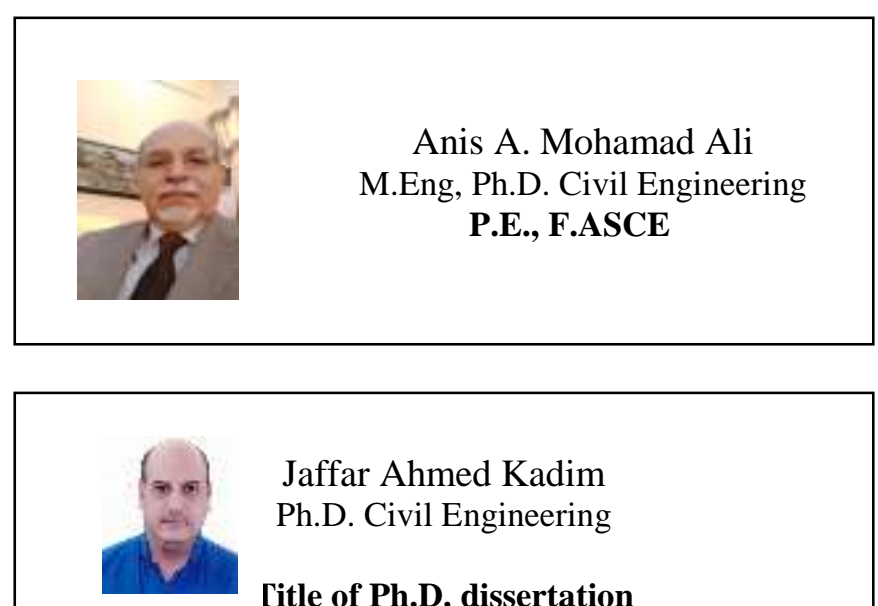

Jaffar Ahmed Kadim Ph.D. Civil Engineering

Citle of Ph.D. dissertation

Dynamic Analysis of Offshore Structures using Finite Element Method 2012 